\title{
Ácido tricloroacético, una opción terapéutica en la hiperplasia epitelial focal. Presentación de un caso
}

\section{Trichloroacetic acid, a therapeutic option in the focal epithelial hyperplasia. Presentation of a case}

\author{
Harris Ricardo J*, Rebolledo Cobos $\mathrm{M}^{* *}$, Camacho Chaljub F***, \\ Carmona Lorduy $M * * * *$, Díaz Caballero $A * * * *$
}

\section{RESUMEN}

La Hiperplasia Epitelial Focal es una patología que se caracteriza por la presencia de múltiples pápulas en la mucosa de la cavidad oral, es de etiología viral, producida por subtipos del papiloma virus humano 13 y 32 , normalmente se presenta en niños y adolescentes, rara vez afecta a adultos, las lesiones se encuentran con mayor frecuencia en las mucosas labial, yugal y lingual. Entre las diferentes alternativas de tratamiento se encuentra la quirúrgica, criocirugía, vitamina $A$, nitrógeno líquido.

El ácido tricloroacético es utilizado en el tratamiento de infecciones con papiloma virus humano como condiloma, papiloma, verrugas vulgares en la mucosa vaginal arrojando buenos resultados presentándose resolución de las lesiones y mucosa vaginal en buen estado. Se reporta caso de paciente femenina de 10 años de edad, remitida al servicio de estomatología y cirugía oral de la universidad de Cartagena por dermatología con diagnostico histopatológico de hiperplasia epitelial sin atipias; al examen clínico se observaron múltiples pápulas en mucosa bucal, color rosado pálido, de consistencia blanda, base sésil, tamaño variables (2-4 mm) de diámetro, asintomáticas y de un años de evolución. Como terapéutica de las lesiones se decide la aplicación de ácido tricloroacético a saturación, observándose resolución de las lesiones con dos topicaciones.

Palabras clave: Hiperplasia epitelial focal, ácido tricloroacético.

\section{SUMMARY}

Focal epithelial hyperplasia is a condition that is characterized by the presence of multiple papules on the mucosa of the oral cavity is of viral etiology, caused by human papilloma virus subtypes 13 and 32, usually occurs in children and adolescents rarely affects adults, injuries are more frequently in the labial mucosa, buccal and lingual. Among the various treatment alternatives is the surgery, cryosurgery, vitamin A, liquid nitrogen.

* Odontólogo. Universidad del Sinú. Residente Estomatología y Cirugía Oral, Universidad de Cartagena.

** Odontóloga. Fundación Universitaria San Martín Sede Caribe. Residente de Estomatología y Cirugía Oral Universidad de Cartagena.

*** Médico. Universidad de Cartagena. Especialista en Dermatología Universidad Santa Casa Misericordia de Sao Pablo, Profesor titular Universidad de Cartagena.

**** Odontóloga. Universidad de Cartagena. Especialista en Estomatología Oral. Universidad de Buenos Aires, Profesor titular Universidad de Cartagena.

***** Odontólogo. Universidad de Cartagena. Especialista en Periodoncia Universidad Javeriana. Profesor titular Universidad de Cartagena. 
Trichloroacetic acid is used in the treatment of infections with human papilloma virus condyloma, papilloma, warts in the vaginal mucosa vulgares successful resolution of the lesions appearing vaginal mucosa and in good condition. We report the case of female patient, aged 10, sent to the service of dentistry and oral surgery at the University of Cartagena in dermatology with histopathological diagnosis of epithelial hyperplasia without atypia, the clinical examination were multiple papules in the oral mucosa, pale pink of soft consistency, base sessile, variable size $(2-4 \mathrm{~mm})$ in diameter, asymptomatic, and one years of evolution. Treatment of injuries such as deciding on the application of trichloroacetic acid to saturation, with resolution of lesions with two topical applications.

Key words: Focal epithelial hyperplasia, trichloroacetic acid.

Fecha de recepción: 5 de junio de 2009.

Aceptado para publicación: 20 de junio de 2009.

Harris Ricardo J, Rebolledo Cobos M, Camacho Chaljub F, Carmona Lorduy M, Díaz Caballero A. Ácido tricloroacético, una opción terapéutica en la hiperplasia epitelial focal. Presentación de un caso. Av. Odontoestomatol 2010; 26 (6): 323-328.

\section{INTRODUCCIÓN}

La hiperplasia epitelial focal es una patología que afecta la cavidad oral, también recibe el nombre de enfermedad de HECK por ser este, el autor que en el año 1961 identificó un paciente con la enfermedad en Nuevo México (1). La frecuencia de esta patología presenta variaciones de un entorno geográfico a otro. Helms documentó casos en esquimales de Groenlandia, Sterm en caucásicos de Berlín, Archard, Heck y Stanley relataron casos aislados en indios norteamericanos del estado de Nuevo México, Brasil y Alaska. Estrada en Colombia, realizo estudios en indígenas de Antioquía y Chocó en los cuales observó la presencia de las lesiones en la mucosa oral, pero no se les realizo biopsia $(1,2)$.

La hiperplasia epitelial focal es de etiología viral, producida por el virus del papiloma humano, se relaciona con los serotipos 13 y $32(3,4)$. Otro factor es la presencia de un gen recesivo, razón por la cual algunos autores sugirieran que se trata de una enfermedad de carácter hereditario $(4,5)$.

Al examen clínico se presentan múltiples pápulas, que si se localizan en zonas de roce tendrán la tendencia a la queratinización; las lesiones se presen- tan con mayor frecuencia en la mucosa labial, yugal, área retro comisural, bordes y cara ventral de lengua, por lo general son del mismo color de la mucosa adyacente, bordes definidos, base sésil, superficie lisa o rugosa, tamaño variable entre 0,1 y 0,5 $\mathrm{cm}$ de diámetro, de crecimiento lento, asintomáticas y no se reporta transformación neoplásica maligna (6).

A nivel histológico se caracteriza por la formación de capas de paraqueratina y acantosis extensa, las células epiteliales del estrato espinoso muestran núcleos grandes, con citoplasma vacuolado, que indican una degeneración coilocitósica. Es frecuente la presencia en el estrato espinoso de células o cuerpos mitosoides $(5,7)$. Los diagnósticos diferenciales deben incluir condiloma acuminado, papilomas, verruga vulgar, síndrome de Cowden (6). Esta enfermedad tiene tendencia a la regresión espontánea a largo plazo; entre las diferentes alternativas de tratamiento se encuentra la escisión quirúrgica, criocirugía, vitamina A (9).

El ácido tricloroacético está compuesto por carbono, cloro, oxígeno e hidrógeno; entre las propiedades químicas se presentan el peso molecular 163,39, fórmula química $\mathrm{CCl} 3 \mathrm{COOH}$, temperatura de fusión $58^{\circ} \mathrm{C}$, hace parte de la familia química (ácido car- 
boxílico), temperatura de ebullición $198^{\circ} \mathrm{C}$, pka de 0,6 (10). El ácido desnaturaliza, precipita y destruye las verrugas por coagulación química del tejido afectado, clínicamente se observa un aplanamiento de las lesiones (11).

El ácido tricloroacético es utilizado en el tratamiento de infecciones con papiloma virus a nivel vaginal en afecciones como condiloma, papiloma, verrugas vulgares. Méndez et al, en un estudio realizado en México, valoraron el tratamiento de la infección cervical por el virus papiloma humano con ácido tricloroacético al $85 \%$. Se analizaron 60 pacientes con diagnóstico de condiloma cervical, tratados con tres aplicaciones semanales de ácido tricloroacético directamente sobre el cérvix. Fueron valoradas después por citología y colposcopia cada tres meses durante un año y se encontró un 73,4\% de curación a los 3 meses (12).

Malviya et al, en un estudio realizado en la universidad del Estado de Wayne, reportó que 46 pacientes con infección ginecológica por papiloma virus humano asociados a displasia, los cuales se les aplicó ácido tricloroacético al $85 \%$ en 18 de estos no se encontró evidencia colposcópica de la infección a las dos semanas, los 28 pacientes restantes presentaron lesiones a la colposcopia y se les realizó una segunda topicación con el ácido, tres meses después del tratamiento no se encontró evidencia de infección por papiloma virus en 31 pacientes (11). Autores como Boothby et al, en Pennsylvania, realizaron un estudio donde aplicaron el ácido en pacientes afectados con papiloma virus humano al $50 \%$ en el cual no se obtuvieron los resultados esperados (13).

El epitelio vaginal es plano estratificado no queratinizado las más profundas son cuboides, las del medio poliédricas y las de la superficie son planas (14). Este tipo de epitelio es similar en algunos sectores de la cavidad oral como los carrillos, mucosa labial, piso de boca, cara ventral de lengua (15). Teniendo en cuenta que es el mismo epitelio y virus (HPV) se implementó la anterior terapéutica en la mucosa oral en un paciente con diagnostico histológico de hiperplasia epitelial focal para observar el comportamiento clínico de la patología ante esta opción terapéutica.

\section{CASO CLÍNICO}

Paciente de sexo femenino 10 años de edad que acude a consulta por presentar múltiples pápulas en mucosa bucal, la madre reporta tiempo de evolución de un año y que aumentan en número con el pasar del tiempo. Relata además un tratamiento anterior hace 6 meses y reporta que las lesiones persistieron; motivo por el cual consulta al médico general quien remite a dermatología donde se practica biopsia de mucosa oral con diagnóstico histológico de hiperplasia epitelial sin atipias. El dermatólogo remite al servicio de estomatología y cirugía oral para su tratamiento. A la valoración por el servicio los antecedentes familiares y personales no son relevantes para el caso y niega alteraciones en órganos y sistemas.

Al examen intraoral presenta múltiples pápulas de forma redondeada, superficie lisa en su mayoría y otras con aspecto moriforme ubicadas en mucosa labial inferior y superior, en tercio anterior de mucosa yugal y borde lateral de lengua lado izquierdo, de tamaño variable (2-4) $\mathrm{mm}$ de diámetro, de color

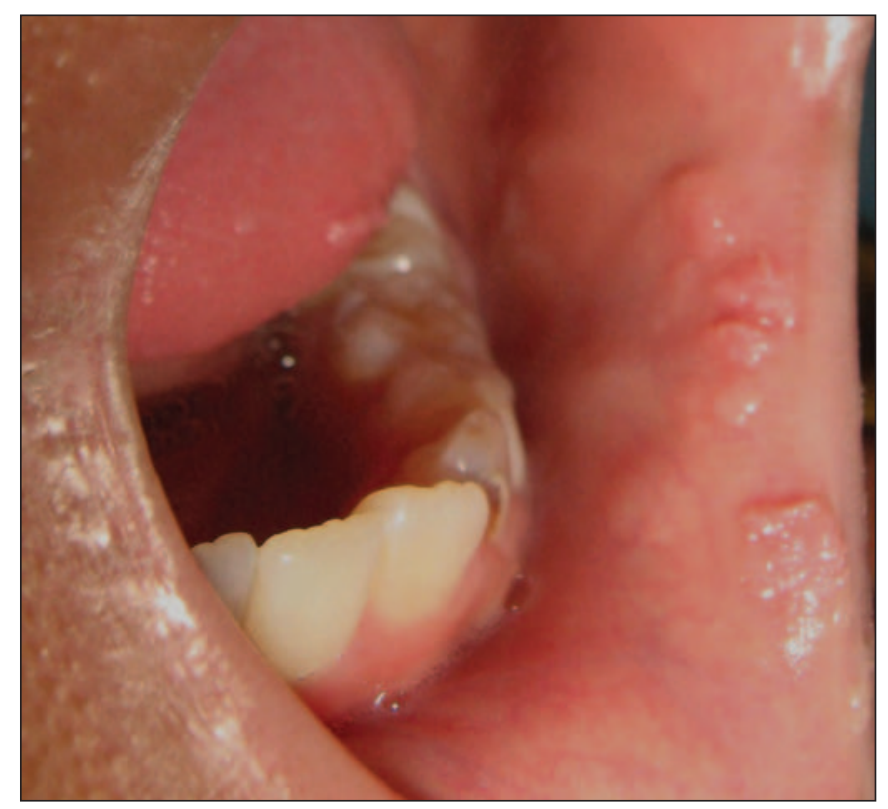

Fig. 1. Descripción de la lesión: múltiples pápulas de forma redondeada, localizadas en tercio anterior de mucosa yugal y mucosa labial inferior lado izquierdo, superficie irregular, tamaño variable (2-4) mm de diámetro, de color rosado pálido, consistencia blanda a la palpación, base sésil. 


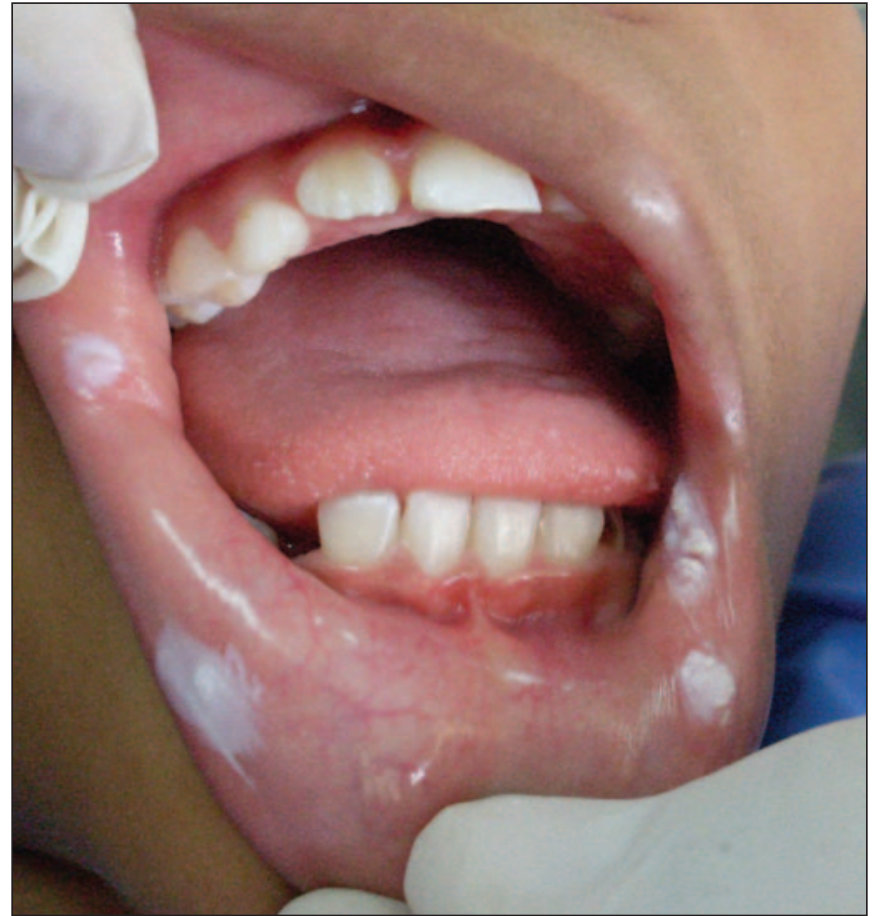

Fig. 2. Topicación de las lesiones con ácido tricloroacético a saturación, presentan una coloración blanca intensa por la quemadura química que produce el ácido.

rosado pálido, consistencia blanda a la palpación, base sésil, asintomática y de 1 año de evolución. El reporte histopatológico describe hiperplasia epitelial sin atipias.

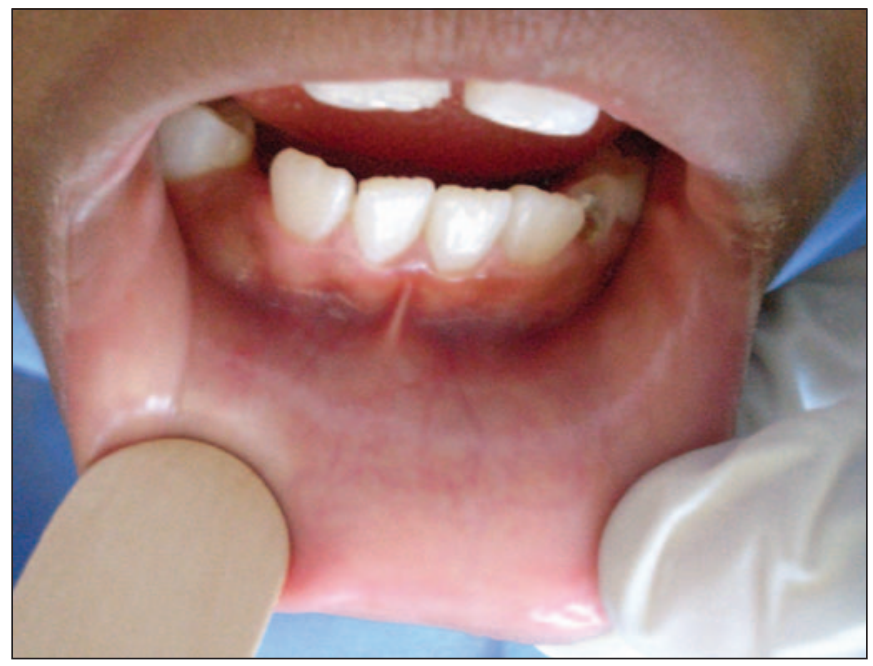

Fig. 3. Descripción: se observa resolución de las lesiones, mucosa oral con características normales, vascularizada, húmeda, brillante, buena elasticidad.
Se define en una junta estomatológica la aplicación del ácido tricloroacético teniendo en cuenta la presencia de múltiples lesiones, edad y el alto nivel de ansiedad de la paciente, con el fin de evitar procedimientos traumáticos, se le explica a la madre las características del tratamiento, esta accede firmando el consentimiento informado.

\section{MODO DE APLICACIÓN}

Los pasos a seguir para la aplicación del ácido se basaron en el protocolo del manejo ginecológico, las topicaciones se realizaron a cada lesión para tener mejor control del ácido tricloroacético en líquido a saturación.

1. Lavar con abundante agua la lesión

2. Secar toda la superficie de la lesión.

3. Topicar una de las lesiones con el ácido tricloroacético con un hisopo, pasados 50 segundos de la aplicación, la lesión toma una coloración blanca intensa por la quemadura química que produce el ácido.

4. Aplicar en la cavidad oral una mezcla de agua y bicarbonato en polvo con un atomizador, para neutralizar el PH del ácido y eliminar residuos que puedan afectar tejidos adyacentes.

5. Repetir el proceso en las otras lesiones.

Después de las cuatro semanas se realiza el primer control observándose resolución de las lesiones en casi todas las superficie excepto en mucosa yugal izquierda tercio anterior en donde se observó única lesión de menor tamaño a la observada en el examen intraoral inicial, se decide aplicar una segunda topicación sobre la lesión persistente y se controló a las dos semanas notándose ausencia de esta y mucosa en buen estado.

\section{DISCUSIÓN}

La hiperplasia epitelial focal es una patología que se caracteriza por la presencia de múltiples pápulas (1). Se le encuentra principalmente afectando mucosa labial, yugal, lengua y las comisuras (2), lo que se confirma en este caso, en el cual se presentaron las lesiones en mucosa labial, yugal y lengua, presenta 
etiología viral, producida por subtipos del virus del papiloma virus humano 13 y $32(3,4)$.

Puesto que existen pocas referencias bibliográficas sobre la aplicación del ácido tricloroacético en cavidad oral y teniendo en cuenta la similitud epitelial del tejido vaginal y la mucosa oral y que es el papiloma virus humano quien los afecta, se comparan los resultados con los del Malviya et al, en un estudio realizado en la Universidad del Estado de Wayne (1987), el cual reportó que 46 pacientes con infección ginecológica por papiloma virus humano, los cuales se les aplicó ácido tricloroacético al $85 \%$ en 18 de estos no se encontró evidencia colposcópica de la infección a las dos semanas, los 28 pacientes restantes presentaron lesiones a la colposcopia y se les realizó una segunda topicación con el ácido obteniendo buenos resultados y con el estudio realizado por Méndez et al, en el que valoraron el tratamiento de la infección cervical por el virus papiloma humano con ácido tricloroacético al $85 \%$. Se analizaron 60 pacientes con diagnóstico de condiloma cervical, tratados con tres aplicaciones semanales de ácido tricloroacético. Fueron valoradas después por citología y colposcopia cada tres meses durante un año y se encontró un 73,4\% de curación a los 3 meses; en este caso se observó resolución de las lesiones en casi toda la superficie de la mucosa oral afectada, después de cuatro semanas de la topicación, excepto en mucosa yugal izquierda, en donde se observó una lesión de menor tamaño a la inicial, se realiza una segunda topicación sobre dicha lesión y a las dos semanas se nota la ausencia de ésta.

Se recomienda investigación referente a la aplicación del ácido tricloroacético a saturación en la cavidad oral sobre las lesiones producidas por el papiloma virus humano, puesto que es una alternativa de tratamiento poco traumática, de bajo costo y con buenos resultados.

\section{BIBLIOGRAFÍA}

1. Rosa LN, Gedoz L, Hildebrand LC, Carvalho A, Chevarría MG. Hiperplasia Epitelial Focal: ¿̇por qué Enfermedad de Heck? Av Odontoestomatol 2003 Mar; 19:239-46.
2. Segura R, Toro M, Ceballos A, Aparicio J, Fuentes $\mathrm{H}$. Focal epithelial hyperplasia. A rare disease in our area. Med Oral Patol Oral Cir Bucal 2005 Mar-Apr;10(2):128-31.

3. Bassioukas K, Danielides V, Georgiou I, Zagorianakou P, Skevas A. Oral focal epithelial hyperplasia. Eur J Dermatol 2000 jul;10(5): 395-7.

4. Cuberos V, Pérez J, López CJ, Castro F, González LV, Correa LA, et al. Molecular and serological evidence of the epidemiological association of HPV 13 with focal epithelial hyperplasia: a casecontrol study. J Clin Virol. 2006 Sep;37(1):21-6. Epub 2006 Jun 21.

5. González L, Gaviria A, Sanclemente G, Rady P, Tyring S, Correa L, et al. Clinical, histopathological and virological findings in patients with focal epithelial hyperplasia from Colombia. Int $\mathrm{J}$ Dermatol. 2005 Apr; 44(4):274-9.

6. Ledesma C, Vega E, Garcés M, Cardiel M, Juárez C. Multifocal epithelial hyperplasia. Report of nine cases. Med Oral Patol Oral Cir Bucal. 2005NovDic;10(5):394-401.

7. González B. Hallazgos histológicos de inmunohistoquímica y ultraestructural en hiperplasia epitelial focal. Ciencia Ergo Sum. 2000 Jul-Oct; 7(2):121-5.

8. Borborema C, Santos M, Benevides P, Talhari S, Astolfi S. Oral Focal Epithelial Hyperplasia: Report of Five Cases. Braz Dent. 2006; 17:79-82. Epub 2006 May 2.

9. Ficha de Datos de Seguridad Según Reglamento (CE) 1907. Citado 2006. www.panreac.com/ new/esp/fds/esp/X151067.htm

10. Beutner KR, Wiley DJ, Douglas JM, Tyring SK, Fife K, Trofatter K. Genital warts and their treatment. Clin Infect Dis. 1999 Jan;28 Suppl $1:$ S37-56.

11. Méndez J, Gónzalez J, Rodríguez J, Muñoz R, Bailón R. Treatment of cervical infection by 
human papilloma virus (HPV) with trichloroacetic acid. Ginecol Obstet Mex. 1993 Feb;61:48-51.

12. Malviya VK, Deppe G, Pluszczynski R, Boike G. Trichloroacetic acid in the treatment of human papillomavirus infection of the cervix without associated dysplasia. Obstet Gynecol 1987 Jul;70 (1):72-4.

13. Boothby RA, Carlson JA, Rubin M, Morgan M, Mikuta J. Single application treatment of human papillomavirus infection of the cervix and vagina with trichloroacetic acid: a randomized trial. Obstet Gynecol 1990 Aug;76(2):278-80.

14. Melo A, Roa I, Montenegro S, Capurro I, Roa JC. Detection of human papilloma virus in cytologic samples or biopsies of the cérvix. Rev Med Chil 2005 Jun;133(6):639-44.

15. Samar M, de Ferraris M, Avila R, de Fabro S, Ferraris R. Human lingual organogenesis: histochemical and ultrastructural aspects. An Fac Odontol 1990 Dec;(26):5-19.

\section{CORRESPONDENCIA}

Jonathan Harris Ricardo

Barrio los Alpes transversal 74 \# 31 g 53.

Cartagena. D.T y C.

Colombia

Correo electrónico: j.harris.r@hotmail.com 